\title{
Cerebellar cortical dysplasia, chronic headache, and tremor in Proteus syndrome
}

\author{
Displasia cortical cerebelar, cefaleia crônica e tremor na síndrome de Proteus
}

Eduardo Rafael Pereira, Valter Malaguido Clímaco, Helvércio Fernando Polsaque Alves

The patient was a 19-year-old woman with chronic headache, hand tremor, and school difficulties. The examination revealed large subcutaneous nodules, epidermal nevus, gigantism of the feet, hypertrophy of the hemibody, and mild postural hand tremor. The magnetic resonance imaging (MRI) showed distortion in the morphology of cerebellar folia, increased size of the cerebellum, and foci hypersignal on
T2 (Figure). Based on diagnostic criteria published, this person has Proteus syndrome ${ }^{1}$.

Proteus syndrome is characterized by exaggerated and asymmetric growth of tissues, and etiology remains not understood, which is probably related to genetic mosaicism. The neurological manifestations include cortical dysplasia, mental retardation, epilepsy, brain tumors, and malformations in the posterior fossa ${ }^{2-4}$.
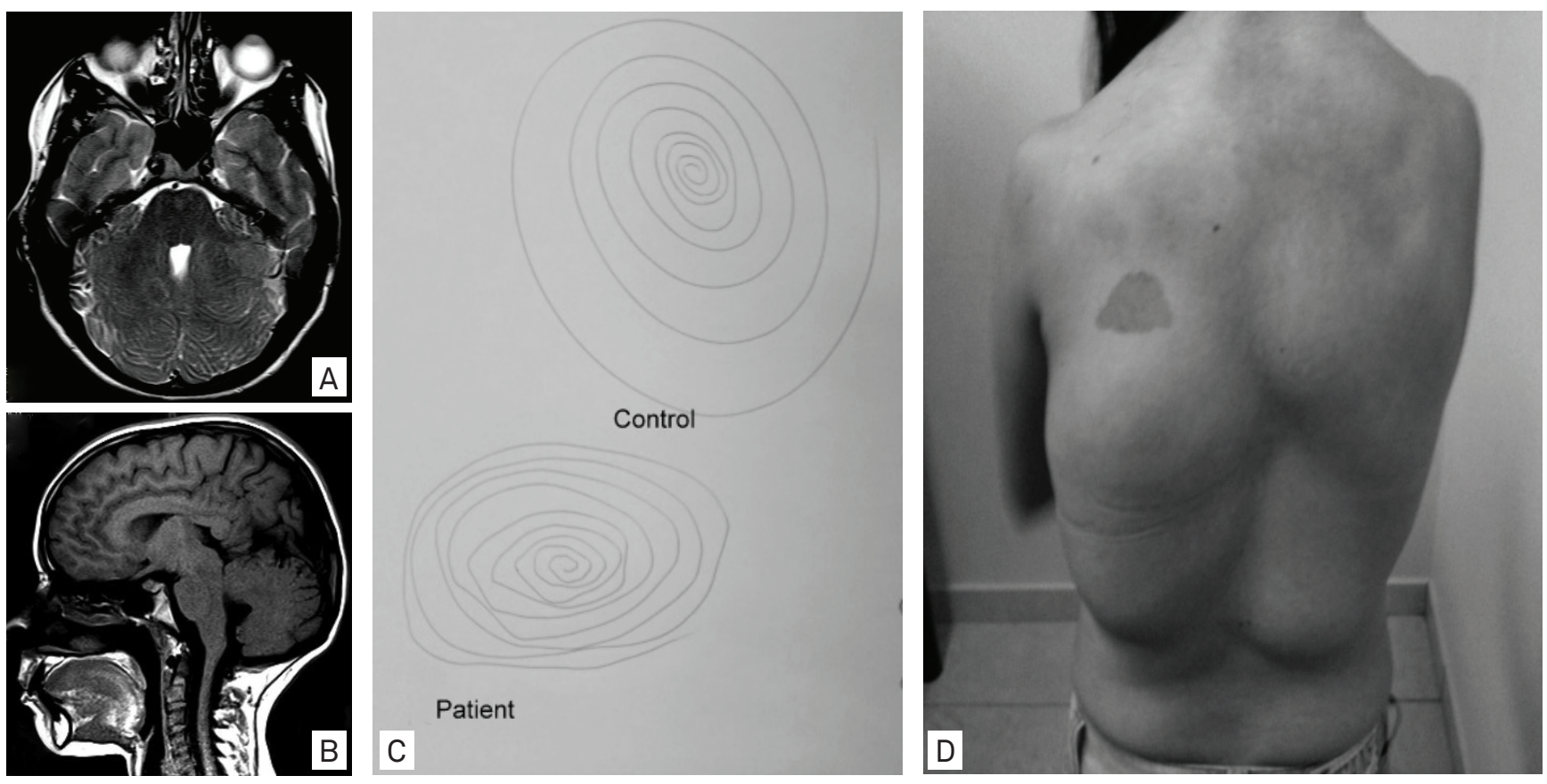

Figure. Axial T2-weighted MRI showed generalized cortical cerebellar dysplasia and deep cerebellar hyper intensities (A); sagittal T1-weighted MRI showed dysplasia of the lower cerebellum (B); tremor in spiral drawing (C), and large subcutaneous nodules, epidermal nevus and hypertrophy of the right hemibody (D).

\section{References}

1. Biesecker LG, Happle R, Mulliken JB, et al. Proteus syndrome: diagnostic criteria, differential diagnosis, and patient evaluation. Am J Med Genet Part A 1999;84:389-395.

2. Dietrich RB, Glidden DE, Roth GM, Martin RA, Demo DS. The Proteus syndrome: CNS manifestations. Am J Neuroradiol 1998;19:987-990.
3. Patel S, Barkovich AJ. Analysis and classification of cerebellar malformations. Am J Neuroradiol 2002;23:1074-1087.

4. McKusick VA. Proteus Syndrome. 1986. [Internet]. [cited 2011 June 15]. Available from: http://www.ncbi.nlm.nih.gov/omim/176920. 